\title{
INTEGRAÇÃO ENTRE ESTRATÉGIA COMPETITIVA E PRÁTICAS DE RESPONSABILIDADE SOCIAL CORPORATIVA: UM ESTUDO EXPLORATÓRIO NOS CINCO MAIORES SUPERMERCADOS BRASILEIRO
}

\author{
Kavita Miadaira Hamza \\ Doutora em Administração de Empresas pela Universidade de São Paulo - USP \\ Professora na Universidade Presbiteriana Mackenzie \\ kavitinha@gmail.com \\ Denise de Abreu Sofiatti Dalmarco \\ MBA em Gestão da Sustentabilidade pela Fundação Getulio Vargas - FGV \\ dsofiatti@yahoo.com
}

\begin{abstract}
RESUMO
Discute-se, por meio deste artigo, a integração das práticas de responsabilidade social corporativa (RSC) e de sustentabilidade, às estratégias competitivas das organizações no setor varejista. Parte-se de uma revisão da literatura com ênfase na evolução das teorias sobre estratégia competitiva e RSC, tendo como base modelo proposto por Porter e Kramer (2006) e em sua ampliação por Aligleri (2008). Em seguida, relatam-se os resultados de uma pesquisa empírica exploratória, com o método de estudo de caso múltiplo com coleta de dados secundários. Esta pesquisa foi feita com os cinco maiores supermercados brasileiros, conforme classificação da Abras em 2009, dos quais apenas os três maiores possuem relatórios de sustentabilidade. A análise dos resultados da pesquisa empírica aponta que os três supermercados possuem práticas de RSC nas quatro etapas do modelo, evidenciando que neste setor já há alguma integração destas práticas com as estratégias das empresas. No entanto, este estudo mostra que ainda há espaço para um maior alinhamento neste sentido.
\end{abstract}

Palavras-chave: Estratégia competitiva; Responsabilidade social corporativa; Sustentabilidade; Varejo.

\section{INTEGRATION OFCOMPETITIVE STRATEGY AND CORPORATE SOCIAL RESPONSIBILITY PRACTICES: AN EXPLORATORY STUDY IN THE FIVE MAJOR BRAZILIAN SUPERMARKETS}

\begin{abstract}
This paper discusses the integration of the practices of corporate social responsibility (CSR) and sustainability, with the competitive strategies of organizations, emphasizing the retail sector. It starts with a literature review focused on the evolution of theories of competitive strategy and CSR, focused on the model proposed by Porter and Kramer (2006) and its extension by Aligleri (2008). Then the results of this exploratory and empirical research, with the method of multiple case studies with secondary data collection, are reported. The survey was conducted with the top five Brazilian supermarkets, according to classification of Abras in 2009, of which only the biggest three have sustainability reports. The results of empirical research indicate that the three supermarkets have CSR practices in the four stages of the model, showing that, in this sector, there is already some integration of these practices with the companies' strategies. However, the study also shows that there is still room for greater alignment in this direction.
\end{abstract}

Key words: Competitive strategy; Corporate social responsibility; Retail; Sustainability. 


\section{INTRODUÇÃO}

A evolução das teorias sobre estratégia competitiva, responsabilidade social corporativa (RSC) e sustentabilidade têm sido bastante representativa e discutida por diversos autores ao longo do tempo. No que tange à estratégia competitiva, nota-se uma evolução da proposta de Porter (1986) para a atualidade, como a visão baseada em recursos defendida por Hamel e Prahalad (1995) e Harrison (2005). Com relação à RSC e à sustentabilidade, apesar de serem considerados por alguns críticos como "assuntos atuais", desde a década de 1930 já são encontradas publicações que mostram a preocupação da sociedade e das empresas com relação a esses temas.

Harrison (2005) aponta a importância de a corporação considerar os diversos públicos de interesse (stakeholders) em seu planejamento, como forma de obter desempenho superior no longo prazo. E a discussão acerca dos stakeholders ganha cada vez mais destaque em razão do aumento da importância da RSC e da sustentabilidade. No entanto, Porter e Kramer (2006) apontam que as discussões sobre RSC ainda são muito fragmentadas, e que falta maior conexão entre este tema e as teorias acerca da estratégia competitiva. Verificou-se, nesse aspecto, que muitas empresas ainda tratam a RSC como um tema à parte de suas decisões de mercado, e não como um elemento a mais a ser considerado no delineamento de suas estratégias. A incorporação das ações de RSC no planejamento dos negócios pode ser uma boa fonte de oportunidades, inovações e vantagem competitiva.

Esta realidade torna-se ainda mais evidente quando analisa-se o setor varejista, que apenas recentemente desenvolveu seus primeiros estudos, nos quais aponta as relações entre o desenvolvimento de ações de RSC e as estratégias competitivas das organizações. Neste sentido, Aligleri (2008) traz uma importante contribuição para o setor supermercadista, subsidiando seu processo decisório para a definição, integração e articulação de políticas socialmente e ambientalmente responsáveis, por meio da ampliação do modelo proposto por Porter e Kramer (2006).

Este artigo trata da relação entre estratégias competitivas e RSC, e tem como objetivo principal compreender como as teorias vêm evoluindo, no que diz respeito à incorporação das práticas da RSC pelas empresas, de forma mais estratégica e integrada ao seu negócio principal. Como objetivo secundário, buscou-se analisar as práticas de RSC do setor supermercadista no Brasil, e o quanto estas são ações mais responsivas ou estratégicas, de acordo com os modelos de Porter e Kramer (2006) e Aligleri (2008).

\section{REVISÃO TEÓRICA}

$\mathrm{Na}$ revisão teórica, buscou-se analisar os aspectos relacionados inicialmente à estratégia competitiva. Em seguida, foi feito um apanhado histórico da responsabilidade social corporativa (RSC) e da sustentabilidade. Após a análise destes dois tópicos, de forma separada, foi realizado um levantamento dos estudos de estratégia competitiva aliados à RSC e/ou à sustentabilidade. Por fim, foram levantados estudos sobre RSC e sustentabilidade aplicados ao setor varejista, que é o foco deste estudo.

\subsection{Estratégia competitiva}

As empresas, ao definirem suas estratégias competitivas, têm como objetivo obter desempenho superior ao de seus concorrentes (Porter, 1986). Ao analisar o contexto das organizações, nota-se que as estratégias desenvolvidas não têm como foco serem as melhores em termos absolutos, mas sim em termos relativos (Ohmae, 1985). Para Henderson (1991), a estratégia competitiva é uma busca deliberada por uma vantagem competitiva. É fundamental, ainda, destacar o clássico modelo das cinco forças competitivas de Porter (1979), que contempla: (I) ameaça de novos entrantes; (II) poder de negociação dos fornecedores; (III) poder de negociação dos

Revista de Gestão Social e Ambiental - RGSA, São Paulo, v. 6, n. 3, p. 78-95, set./dez. 2012. 
compradores; (IV) ameaça de produtos ou serviços substitutos e (V) rivalidade entre as empresas existentes. Barroso de Siqueira (2005) ressalta que existe, ainda, uma sexta força neste modelo, que seria o Poder do Estado.

A estratégia competitiva deve então relacionar a empresa ao seu meio ambiente e encontrar uma posição para que a empresa possa melhor se defender contra tais forças, ou ainda influenciá-las a seu favor. Para lidar com estas forças competitivas, Porter (1986) sugere a clássica abordagem das estratégias genéricas: (I) liderança no custo total; (II) diferenciação; e (III) enfoque.

Enquanto o modelo de estratégia competitiva proposto por Porter (1986) tem o enfoque no ambiente externo à organização, o modelo da visão baseada em recursos dá mais ênfase aos recursos internos, em que as habilidades e capacidades dominadas por uma organização podem levá-la a um desempenho superior. Segundo Penrose (1959 apud Harrison, 2005), a empresa pode ser vista como uma estrutura que coordena atividades de diversos grupos ou pessoas, assim como um conjunto de recursos produtivos, que podem influenciar o desempenho competitivo. Harrison (2005) aponta que a visão tradicional é determinista, uma vez que a boa administração estará associada àquela estratégia que melhor se adapta às forças existentes. A importância desta visão não é menosprezada, mas a principal crítica que se faz, é o fato de que a organização pode influenciar seu ambiente, por meio de alianças estratégicas com seus stakeholders, investimentos em tecnologia de ponta, aquisição de patentes, propaganda etc.

Hamel e Prahalad (1995) também defendem a estratégia competitiva do modelo da visão baseada em recursos, e apontam que a competição pelas competências essenciais precede a competição pela liderança de produtos. Assim, concebe a empresa como um conjunto de competências. É importante destacar que a estratégia de uma empresa não deve ser baseada nos seus recursos atuais, e sim na capacidade que a empresa ou seus concorrentes têm em dinamizar tais recursos.

Segundo Hamel e Prahalad (1995), a competência é um conjunto de habilidades e tecnologias integradas de tal forma que fornecem uma vantagem competitiva para a empresa. Para que uma competência seja essencial, ela deve: (I) ser percebida e valorizada pelo cliente; (II) proporcionar uma diferenciação da empresa, ser única ou muito superior aos concorrentes, e (III) a empresa deve ser capaz de expandi-la para novos produtos, serviços ou aplicações. Segundo Harrison (2005, p.79), “[...]se um recurso ou aptidão é valioso, único, insubstituível, difícil de imitar, e se puder ser aplicado a mais de uma área de negócios, é chamado de competência ou aptidão básica".

Os recursos podem ser tangíveis ou intangíveis, mas, em geral, os tangíveis são mais passíveis de imitação, enquanto os intangíveis, como conhecimento, reputação organizacional, boa relação com stakeholders, marca corporativa bem conhecida, são mais difíceis de imitar. Portanto, os recursos intangíveis são os que têm maior chance de gerar uma vantagem competitiva para a organização. E, de acordo com Barney e Arikan (2001 apud Harrison, 2005), se eles forem caros ou impossíveis de imitar, a empresa pode obter um desempenho superior durante um longo período.

Harrison (2005) destaca, no entanto, que estes recursos estão indo além das fronteiras das organizações, uma vez que estas estão desenvolvendo cada vez mais alianças e contratos que também contribuem para uma estratégia competitiva mais sólida. Todos estes recursos estão fortemente associados aos stakeholders da organização.

Esta visão está alinhada com a teoria dos stakeholders, segundo a qual a corporação é responsável por seus públicos interessados, sem os quais deixaria de existir (Freeman; Reed, 1983). A teoria dos stakeholders aponta que não apenas os acionistas (ou stockholders) devem ser considerados na formulação da estratégia de uma organização, mas também os demais públicos interessados (stakeholders), pois estes afetam e são afetados pelas atividades das empresas. Segundo Harrison (2005), a empresa é o centro de uma rede de públicos, chamados de públicos interessados (PIs), e pode obter vantagem competitiva por meio da gestão do relacionamento com todos estes PIs, e não apenas com os seus consumidores. 
Ao considerar os diversos Pis, a empresa analisa, de forma mais acurada, a natureza complicada da tarefa gerencial de se lidar com tantos grupos de interesse. Além disso, ao considerar os diversos grupos de interesse na formulação da estratégia, a empresa evita ser surpreendida por um determinado grupo insatisfeito. Esta visão permite à empresa um leque maior de opções na seleção de opções estratégicas. A análise dos stakeholders torna-se especialmente importante ao estudar a sustentabilidade nos negócios.

\subsection{Responsabilidade Social Corporativa (RSC) e Sustentabilidade nos Negócios}

Os temas da RSC e da Sustentabilidade nos Negócios tomaram força nos últimos anos e estão cada vez mais em pauta nas empresas e na academia. No entanto, essas questões não são novas, e sim assuntos que têm evoluído há décadas.

Segundo Carroll (1999), há evidências do interesse das empresas pela comunidade há séculos, sendo que o referencial teórico data de 1938. Cheit (1964) reforça este aspecto, apontando que, na década de 1960, já existia a "onda" do movimento da responsabilidade social. O autor (idem, 1964) afirma, ainda, que este movimento já não era novo para a época, sendo que vinte anos antes, empresários e executivos já estavam engajados em uma campanha para fortalecer suas imagens e promover um novo entendimento de seus papéis na sociedade. Outra evidência, de acordo com Cheit (1964), é a conferência anual de ex-alunos da Harvard Business School de 1948, que teve como tema principal a Responsabilidade Corporativa.

Outro autor que trata da RSC na década de 1960 é Keith Davis, que afirma que as empresas deveriam desempenhar determinados papéis e funções na e para a sociedade, com especial atenção à sua responsabilidade em razão das decisões de negócios tomadas (Davis, 1960). A RSC se refere às decisões e ações que executivos ou empresários tomam, pelo menos em parte, além de seus interesses econômicos ou técnicos. Por um lado, a empresa reconhece suas contribuições e obrigações com relação ao desenvolvimento econômico da sociedade (oferta de empregos, inflação, manutenção da concorrência etc). De outro, existem os aspectos dos valores humanos que também devem ser desenvolvidos pela empresa, mas que não podem ser mensurados por meio de uma escala econômica (Davis, 1960).

Na mesma década de 1960, também vemos surgir os primeiros questionamentos em relação à sustentabilidade do planeta. Em 1968, surge o Clube de Roma, instituição que reúne pensadores de todo o mundo e de diferentes campos da ciência para promover as mudanças sistemáticas que seriam determinantes para o futuro da humanidade. Peccei (1968), um de seus fundadores, questionava o modo de vida que estava sendo adotado na época e a visão imediatista das pessoas, que não pensavam na consequência de seus atos no longo prazo.

Em 1972, com o apoio do Clube de Roma, um grupo de estudantes do MIT publicou um estudo emblemático chamado Os Limites do Crescimento, que teve grande repercussão internacional. Neste estudo, foi utilizado um modelo computacional e a teoria de sistemas dinâmicos para analisar as causas e consequências do crescimento populacional e da economia material/capitalista, com base nisso, concluíram que restrições ecológicas globais (em relação ao uso de recursos e emissões) teriam uma grande influência no desenvolvimento do mundo no século 21. Assim, seria necessária uma inovação profunda e pró-ativa por meio de mudanças tecnológicas, culturais e institucionais, a fim de evitar que o aumento da "pegada ecológica" da humanidade ficasse acima da capacidade que o planeta poderia suportar (Meadows; Raders; Meadows, 2004). No mesmo ano, ocorreu a Conferência das Nações Unidas Sobre Meio Ambiente Humano (Conferência de Estocolmo), que teve o objetivo de chamar a atenção da comunidade internacional para os problemas ambientais globais. Este evento foi um marco referencial sobre a consciência de que era necessário preservar o meio ambiente para que a humanidade pudesse ter uma vida digna no futuro.

Outra importante contribuição para a evolução da discussão sobre sustentabilidade foi dada por Brundtland (1987), com o lançamento do relatório Nosso Futuro Comum. É a partir deste

Revista de Gestão Social e Ambiental - RGSA, São Paulo, v. 6, n. 3, p. 78-95, set./dez. 2012. 
momento que surge o conceito mais amplamente utilizado sobre desenvolvimento sustentável, como aquele que atende as necessidades do presente sem comprometer a possibilidade de as gerações futuras atenderem às suas necessidades (Brundtland, 1987).

Em contrapartida a toda essa discussão, Friedman (1985 apud Borger, 2001) questiona o papel das empresas na sociedade, declarando que elas devem limitar sua responsabilidade social à maximização dos lucros e à obediência à lei. Em sua perspectiva, retrata os negócios como uma autoprocura do lucro, sendo que outras considerações sociais são de responsabilidade da sociedade, e não dos negócios.

Carroll (1979), em contraposição, destaca que as empresas devem contemplar quatro aspectos fundamentais: econômico, legal, ético e filantrópico. Todos eles sempre estiveram de alguma forma presentes nas organizações, porém apenas nas décadas de 1980 e 1990 as funções éticas e filantrópicas receberam destaque. Em acordo com Friedman (1985 apud Borger, 2001), Carroll (1991) destaca que a função econômica deve preceder as demais, sendo que em seguida aparecem as funções legal e ética, sobre as quais todas as atividades da organização devem ser desenvolvidas. Por fim, vai além e aponta que a organização tem ainda funções filantrópicas/voluntárias, de contribuição para a comunidade.

Drucker (1992 apud Borger, 2001) também aponta aspectos da RSC como fundamentais em uma organização. As empresas e os empresários são percebidos como lideranças, que, por sua vez, impõem responsabilidade e integridade pessoal - ou seja, o que os executivos fazem é visto como um exemplo para toda a organização. O autor (idem, 1992 apud Borger, 2001) também questiona a mudança que existe na gestão das empresas, quando seus proprietários passam de acionistas para investidores - mudando o foco do administrador, da busca por resultados no longo prazo para a busca por ganhos mais imediatos.

Esse ponto também é abordado por Handy (2002), que diz que no capitalismo americano das bolsas de valores a medida do sucesso é a riqueza gerada para os acionistas, expressa pelo valor das ações da empresa. Há vários meios de aumentar o valor das ações das empresas, sendo que o curto prazo está sendo privilegiado em detrimento do longo prazo. Um forte exemplo é a remuneração dos altos executivos, composta por uma grande parcela de opções de ações, onde os principais tomadores de decisão buscam aumentar o resultado no curto prazo, a fim de realizarem, o quanto antes, o lucro. Para Handy (2002), as empresas precisam assumir a liderança em áreas como a sustentabilidade ambiental e social. Ao contrário do que prega Milton Friedman, seria necessário ir além de cumprir os requisitos legais relativos ao meio ambiente, às condições do trabalho, às relações com a comunidade e às questões de ética, pois a legislação está sempre defasada em relação às melhores práticas (Handy, 2002).

As discussões sobre RSC e sustentabilidade, como se pode notar, são amplas e complexas, e até por isso, é difícil de avaliar em que momento os dois conceitos se relacionam. Segundo Elkington (1994), a partir da publicação do relatório Nosso Futuro Comum, em 1987, e da Conferência das Nações Unidas para o Meio Ambiente e o Desenvolvimento (Eco-92), o conceito de desenvolvimento sustentável - que envolve a integração do pensamento ecológico em todos os aspectos das atividades sociais, políticas e econômicas - se tornou um ponto central no debate ambiental. A partir de então, evidenciou-se que as empresas devem desempenhar um papel central na aplicação de estratégias para o desenvolvimento sustentável.

Segundo Elkington (1999), dado que as empresas existem para gerar riqueza, a contribuição mais direta que elas podem dar para o desenvolvimento sustentável é a de criar valor econômico, social e ambiental no longo prazo - de onde surge o já bastante disseminado conceito de "triple bottom-line". A base para esse conceito reside no reconhecimento de que para uma empresa prosperar no futuro ela precisa constantemente atender às necessidades da sociedade em termos de bens e serviços, sem destruir os capitais social e ambiental. Este modelo não implica necessariamente em uma nova discussão sobre o objetivo primário das empresas. Pelo contrário, aumenta o horizonte de tempo sobre o qual a gama de interesses de uma empresa deve ser avaliada,

Revista de Gestão Social e Ambiental - RGSA, São Paulo, v. 6, n. 3, p. 78-95, set./dez. 2012. 
o que demanda uma grande mudança organizacional em termos de cultura, valores, processos decisórios e comportamento.

Diversas organizações se mobilizaram nos últimos anos e criaram diferentes formas de atuação no campo da responsabilidade social corporativa. Em 1997, foi idealizado o Global Reporting Iniciative (GRI), uma organização internacional que promove a divulgação das performances econômica, ambiental e social das organizações, assim como já é divulgada atualmente a performance financeira. O GRI busca ser um local de convergência de ideias sobre transparência, prestação de contas, divulgação de informações e desenvolvimento sustentável (Global Reporting Iniciative, 2010).

Também em 1997, um grupo de empresários e executivos do setor privado brasileiro criou o Instituto Ethos de Empresas e Responsabilidade Social, que tem como finalidade mobilizar, sensibilizar e ajudar as empresas a gerir seus negócios de forma socialmente responsável no Brasil (Instituto Ethos, 2010). Em 2000, a Organização das Nações Unidas, lançou o Global Compact:

[...]iniciativa desenvolvida pelo ex-secretário geral da ONU, Kofi Anan, com o objetivo de mobilizar a comunidade empresarial internacional para a adoção, em suas práticas de negócios, de valores fundamentais e internacionalmente aceitos nas áreas de direitos humanos, relações de trabalho, meio ambiente e combate à corrupção refletidos em 10 princípios. Essa iniciativa conta com a participação das agências das Nações Unidas, empresas, sindicatos, organizações não-governamentais e demais parceiros necessários para a construção de um mercado global mais inclusivo e igualitário. (Pacto Global, 2013)

Uma linha de estudos fortemente ligada à responsabilidade social corporativa e à sustentabilidade é a que descreve e analisa a importância dos stakeholders, conforme apontado no tópico 2.1 deste estudo. Freeman e Reed (1983) definem os stakeholders como os grupos pelos quais a corporação é responsável, ou sem os quais a corporação deixaria de existir. Já para Donaldson e Preston (1995), os stakeholders são pessoas ou grupos de pessoas que têm interesses legítimos nas atividades da corporação. Eles podem ser identificados por seus interesses na corporação, quando a corporação tem um interesse correspondente com relação a eles.

Quando se trata da responsabilidade social corporativa, é imprescindível que a organização se atenha às questões levantadas por seus stakeholders. Donaldson e Preston (1995) apontam que a teoria dos stakeholders entende a organização como uma entidade que congrega numerosos e diversos participantes, muitas vezes com propósitos incongruentes. O gerenciamento das diversas, e muitas vezes divergentes, demandas que provêm de cada stakeholder é uma tarefa complexa, que exige a definição de políticas de RSC.

Porter e Kramer (2006) enfatizam que as corporações e a sociedade precisam mudar a forma como vêem uma à outra, mudando o pensamento de responsabilidade social corporativa, para uma integração social corporativa. Desta forma, encarar a RSC como uma oportunidade, e não como controle de riscos ou uma campanha de relações públicas, requer uma mudança radical na forma de pensar e de postura, que se tornará cada vez mais importante para o sucesso competitivo.

\subsection{Estratégia Competitiva e Responsabilidade Social Corporativa (RSC)}

Foram tratadas, separadamente, nos tópicos anteriores, as evoluções das teorias de estratégia competitiva, responsabilidade social corporativa (RSC) e sustentabilidade. No entanto, é de fundamental importância destacar que existe uma forte conexão entre estes temas. Ao analisar a evolução das estratégias competitivas, em especial no que se refere à vertente da visão baseada em recursos, Harrison (2005) já destaca que a corporação é responsável por seus stakeholders. Ao considerá-los em seu planejamento, a estratégia competitiva da organização se torna mais sólida, possibilitando à empresa obter um desempenho superior em longo prazo. Mesmo anteriormente, Carroll e Hoy (1984) já apontavam que os executivos deveriam incluir políticas sociais em suas estratégias de negócios, dos quais derivariam processos e práticas funcionais para serem administradas no dia-a-dia.

Revista de Gestão Social e Ambiental - RGSA, São Paulo, v. 6, n. 3, p. 78-95, set./dez. 2012. 
Mais recentemente, Hart e Milstein (2004) discutem que a opção pela sustentabilidade pode não só contribuir para um mundo melhor, mas também para gerar riqueza no longo prazo. No mesmo sentido, Prahalad, Nidumolu e Rangaswami (2009) defendem que não há outra alternativa para o desenvolvimento sustentável. Mesmo assim, muitas empresas estão convencidas de que quanto mais ambientalmente corretas elas se tornarem, mais esse esforço corroerá sua competitividade. É por essa razão que muitos executivos tratam a necessidade de se tornarem sustentáveis como uma ação de RSC, e não como o objetivo de seu negócio. Os autores (idem, 2009) concluem que a chave para o progresso no mundo hoje é a inovação para a sustentabilidade, o que já começa a transformar o cenário competitivo das empresas, forçando-as a mudar a maneira como pensam seus produtos, suas tecnologias, seus processos e modelos de negócio.

Já Porter e Kramer (2006) apontam que as discussões sobre RSC ainda são muito fragmentadas, e que falta maior conexão entre este tema e as teorias acerca da estratégia competitiva. A falta de discussão destes temas em conjunto não permite que as empresas percebam as melhores oportunidades para contribuir com a sociedade. Os autores (idem, 2006) destacam ainda que a incorporação das ações de RSC no planejamento dos negócios pode ser uma boa fonte de oportunidades, inovações e vantagem competitiva.

A principal crítica que se faz é o fato de que muitas empresas tratam a RSC como um tema à parte de suas decisões de mercado, e não como um elemento a mais a ser considerado no delineamento de suas estratégias. Estas empresas já percebem os riscos associados às cobranças dos stakeholders, mas ainda não sabem como contorná-los. Assim, acabam por não atuar de forma estratégica, nem de forma operacional, ou seja, suas ações acabam por ser apenas superficiais ou "cosméticas". Os Relatórios de RSC, por exemplo, cada vez mais frequentes, são publicações que raramente oferecem informações estruturadas e aprofundadas sobre a atuação social das empresas, e acabam virando mais uma peça de marketing do que um relatório de ações coerentes e consistentes.

Avançando nesta discussão, Porter e Kramer (2006) segmentam as possíveis ações no que denominam de responsabilidade social responsiva e responsabilidade social estratégica. A primeira consiste em atuar como cidadão corporativo, mitigando os impactos adversos da atividade da empresa. Já a segunda implica em fazer algo distinto dos adversários, identificando oportunidades de valor compartilhado com a sociedade. Partindo deste ponto, os autores (idem, 2006) classificam as ações de RSC em quatro etapas, e propõem o modelo apresentado na Figura 1 a seguir.

A RSC responsiva envolve dois elementos. O primeiro deles é a boa cidadania, que envolve manter boas relações com o governo e as pessoas da comunidade em que está inserida, e monitorar as ações desenvolvidas ao longo do tempo, assim como seus resultados. A segunda parte - mitigar danos causados por atividades da cadeia - é um desafio operacional. Muitas empresas usam listas padronizadas de riscos de suas operações, como a do GRI, mas deveriam buscar mapear sistematicamente e de forma mais profunda o seu negócio específico, e então desenvolver um processo para fazer a gestão dos riscos.

Já a RSC estratégica busca uma posição única para a empresa, diferenciando-a de seus concorrentes, por meio do desenvolvimento de iniciativas cujos benefícios sociais e econômicos sejam grandes e distintos. Ela também envolve duas partes, sendo a primeira delas a transformação das atividades da cadeia de valor. De acordo com Porter e Kramer (2006), quanto mais próximo o aspecto social tratado for do negócio da empresa, maiores as oportunidades para integrar os recursos da empresa, e beneficiar a sociedade. No limite, quando isso ocorre fica difícil distinguir a ação social do negócio.

Impactos sociais genéricos

\section{Impactos sociais da} cadeia de valor
Dimensões sociais do contexto competitivo

Revista de Gestão Social e Ambiental - RGSA, São Paulo, v. 6, n. 3, p. 78-95, set./dez. 2012. 


\begin{tabular}{|c|c} 
Boa cidadania & $\begin{array}{c}\text { Mitigar danos causados por } \\
\text { atividades da cadeia de valor } \\
\text { alavanca recursos para } \\
\text { melhorar áreas relevantes do } \\
\text { contexto competitivo }\end{array}$ \\
RSC Responsiva & $\begin{array}{c}\text { Transformar atividades da } \\
\text { cadeia de valor para }\end{array}$ \\
beneficiar a sociedade e ao & RSC Estratégica \\
& mesmo tempo fortalecer a
\end{tabular}

Figura 1: Envolvimento corporativo na sociedade: uma abordagem estratégica

Fonte: Porter, M. E.; Kramer, M. R. (2006)

A segunda parte da RSC estratégica é a filantropia estratégica, que ocorre quando a empresa coloca uma dimensão social em sua proposta de valor, integrando o impacto social de sua atividade à sua estratégia de negócios. Nesse sentido, a RSC é um diferencial competitivo, buscando uma proposição única de valor, ou seja, atender um conjunto de necessidades de seu público-alvo que outras empresas não conseguem atingir. As empresas que atuam neste estágio percebem que as grandes oportunidades de negócio resultam da integração de seus negócios com melhorias na sociedade.

Elkington (1994) também destaca que um grande desafio para as empresas é justamente desenvolver novas formas de cooperação com seus stakeholders, assegurando que haverá não apenas benefícios sociais, mas também o desenvolvimento de uma vantagem competitiva.

\subsection{Responsabilidade Social Corporativa e Sustentabilidade no Varejo}

A discussão sobre RSC e sustentabilidade no varejo é bastante recente, e começou a ganhar mais força na década de 2000. No Brasil, em 2003, o Centro de Excelência em Varejo da FGVEAESP (GVCEV) lançou o prêmio de Responsabilidade Social e Sustentabilidade no Varejo, buscando reconhecer e incentivar projetos desenvolvidos por empresas e entidades varejistas de todo o Brasil.

Para Macedo (2005), desenvolver a RSC no varejo também é uma forma de permear as práticas socialmente responsáveis por toda a cadeia de valor, estabelecendo relações transparentes que vão desde a fabricação de um produto ou criação de um serviço, passando pelos compromissos éticos dos fornecedores e atacadistas (distribuidores), pela forma de comercialização determinada pelas empresas varejistas e, sobretudo, pela decisão de compra consciente do consumidor, que tem a possibilidade de privilegiar uma empresa em detrimento de outra no mercado. Por outro lado, Hamza e Dalmarco (2011) apontam que o principal fator de escolha do supermercado em consumidores das classes A e B ainda é a localização conveniente, sendo que os aspectos relacionados à RSC e sustentabilidade são poucos relevantes, de um total de 13 fatores analisados.

Macedo (2008) destaca que o setor varejista possui características que favorecem as práticas socialmente responsáveis, que são: proximidade e articulação social nas regiões onde atua; papel modificador na cadeia de valor (pela proximidade com os consumidores); representatividade e capilaridade geográfica; e capacidade de mobilização dos setores varejistas (por meio de associações do setor).

Em 2005, o GVCEV lançou, em conjunto com o Instituto Ethos, um Guia de Indicadores de Responsabilidade Social nas Empresas Varejistas, com o intuito de oferecer às empresas do setor uma ferramenta para auxiliar no processo de incorporação da responsabilidade social em sua gestão. Cardoso (2008, p.71) destaca que "[...]a despeito da relevância do varejo para a promoção de práticas de responsabilidade social, constatamos, com perplexidade, que poucas empresas do setor demonstram ter esse componente inserido na gestão do negócio". 
Mesmo estudos internacionais que apontam ações de RSC e/ou sustentabilidade no varejo são recentes, como os desenvolvidos em: Reino Unido (Jones et al., 2005), Suécia (Anselmsson; Johansson, 2007), Austrália e Nova Zelandia (Harris, 2007) e África do Sul (Dos Santos, 2009).

Jones et al. (2005) avaliaram como os 20 maiores varejistas do Reino Unido comunicam seu posicionamento e atuação em relação a RSC e sustentabilidade, usando como base o triple bottomline. Este estudo aponta que estas empresas reconhecem que seus negócios têm impacto no meio ambiente, na economia e na sociedade, e buscam monitorá-los ao desenvolver suas ações de sustentabilidade. Por fim, concluem que os varejistas acreditam que a integração destas ações ao seu negócio fortalece sua posição no mercado. Na Suécia, Anselmsson e Johansson (2007) conduziram um estudo onde se pode verificar que há espaço para que os varejistas se distinguam dos concorrentes, posicionados em atributos ligados à RSC. Na mesma linha, um estudo conduzido por Harris (2007) com varejistas na Austrália e na Nova Zelândia, aponta que há demanda de consumidores dispostos a pagar preços mais altos por produtos identificados como genuinamente sustentáveis. Um estudo da Unep, Global Compact e Utopies (2005) revela que, apesar de 40\% das pessoas afirmarem estarem predispostas a comprar produtos "verdes", atualmente apenas 4\% compram, de fato, tais produtos. Na África do Sul, Dos Santos (2009) investigou as ações de RSC e sustentabilidade de um grande varejista, e apontou que é possível estimular seus fornecedores a se tornarem socialmente mais responsáveis, em particular quando estes vêem benefícios financeiros nestas ações.

No Brasil, um estudo realizado por Parente e Terepins (2006) investigou a atuação com relação à RSC das cinco maiores empresas varejistas brasileiras. Entre suas conclusões, destacam que não há um padrão de atuação de RSC das grandes empresas varejistas, sendo que se confirma a importância do envolvimento da cúpula das empresas para a incorporação dos valores de RSC na gestão e estratégia geral da organização. Para tanto, a cúpula necessita se conscientizar de que existem formas de RSC que, em sintonia com a missão da empresa, acarretam vantagens competitivas.

Mais recentemente, Aligleri (2008) propõe uma ampliação do modelo de gestão estratégica da responsabilidade social de Porter e Kramer (2006) para o setor supermercadista. São propostas 88 ações a serem realizadas pelos supermercados, divididas em 17 ações de boa cidadania, 28 ações para mitigar danos causados por atividades da cadeia de valor, 34 ações para transformar as atividades da cadeia de valor e 9 políticas de filantropia estratégica. Tais ações são classificadas por área organizacional, tendo sido ainda identificados os stakeholders mais diretamente vinculados.

\section{MÉTODO DE PESQUISA}

Na investigação empírica, foi empregada a pesquisa exploratória que, de acordo com Selltiz, Wrightsman e Cook (1965) e Mattar (1996), é mais apropriada para os estágios iniciais do estudo, quando o pesquisador busca familiarizar-se com o tema. Tal se adequa a este estudo, uma vez que a análise da RSC incorporada à estratégia competitiva, no segmento do varejo, ainda é um tema recente, especialmente no Brasil.

Definido o tipo de pesquisa, procedeu-se a escolha do método de pesquisa, utilizado para se alcançar o objetivo proposto. Roesch (1999) destaca que o estudo de caso é apropriado especialmente quando a ênfase da pesquisa é a análise de fenômenos ou processos em seu contexto, e não traços, opiniões ou ações de indivíduos. Yin (2001) aponta, na mesma linha, que se trata de uma estratégia de pesquisa abrangente, uma investigação empírica onde há mais variáveis de interesse do que pontos de dados, baseando-se em várias fontes de evidências. Neste estudo, optouse pelo estudo de casos múltiplos.

A escolha dos casos, segundo Eisenhardt (1989), é uma importante etapa no método do estudo de caso para construção de teorias, sendo que a escolha deve ser adequada à teoria que se busca construir. Foi utilizada a classificação da Associação Brasileira de Supermercados (Abras) de

Revista de Gestão Social e Ambiental - RGSA, São Paulo, v. 6, n. 3, p. 78-95, set./dez. 2012. 
2009, e selecionados os cinco maiores supermercados (varejo de autosserviço), que representam $43 \%$ do faturamento total do setor.

Foram utilizados dados secundários, por meio da análise dos relatórios de sustentabilidade de cada supermercado, publicados em meio eletrônico, assim como de informações na mídia em geral (jornais, revistas e endereço eletrônico corporativo). Utilizou-se a análise de conteúdo, definida por Bardin (1977, p.31) como "[...] um conjunto de técnicas de análise das comunicações" visando obter, por meio de procedimentos sistemáticos e objetivos de descrição do conteúdo das mensagens, indicadores que permitam a inferência de conhecimentos relativos às condições de produção/recepção destas mensagens. Os dados brutos foram transformados e agregados em unidades de registro, visando à categorização conforme a estrutura proposta por Aligleri (2008).

\section{ANÁLISE DOS DADOS}

Iniciou-se o estudo empírico com a seleção dos maiores varejistas de autosserviço brasileiros. De acordo com Cardoso (2010), o 33 Ranking Abras 2010, elaborado pela Associação Brasileira de Supermercados (Abras), aponta que os cinco maiores supermercados que atuam no Brasil somaram um faturamento de cerca de $\mathrm{R} \$ 76$ bilhões em 2009. Cruzando os dados de Cardoso (2010) com o faturamento do setor (Sato, 2010), nota-se que apenas os cinco maiores representam quase $79 \%$ do faturamento dos vinte maiores supermercados, e $43 \%$ do faturamento total do setor.

Os cinco maiores supermercados são, em ordem decrescente de faturamento: Companhia Brasileira de Distribuição (CBD), Carrefour, Wal-Mart, Gbarbosa e Zaffari. Na figura 2 é apresentada uma breve contextualização das empresas analisadas.

\begin{tabular}{|c|c|c|c|c|c|}
\hline & 1 & 2 & 3 & 4 & 5 \\
\hline & CBD & Carrefour & Wal Mart & GBarbosa & Zaffari \\
\hline $\begin{array}{l}\text { Faturamento/lucro } \\
\text { em } 2009\end{array}$ & $\mathrm{R} \$ 26,22$ bilhões & $\mathrm{R} \$ 25,62$ bilhões & $\mathrm{R} \$ 19,72$ bilhões & $\mathrm{R} \$ 2,49$ bilhões & $\mathrm{R} \$ 2,11$ bilhões \\
\hline $\begin{array}{l}\% \text { faturamento } \\
\text { Brasil } 2009\end{array}$ & $14,8 \%$ & $14,5 \%$ & $11,1 \%$ & $1,4 \%$ & $1,2 \%$ \\
\hline Capital & $\begin{array}{c}50 \% \text { brasileiro } \\
50 \% \text { francês }\end{array}$ & $100 \%$ francês & $100 \%$ americano & $100 \%$ chileno & $100 \%$ brasileiro \\
\hline Atuação/região & $\begin{array}{l}\text { - Sudeste (exceto } \\
\text { ES) } \\
\text { - Sul (exceto SC } \\
\text { e RS) } \\
\text { - Centro-oeste } \\
\text { (exceto MT) } \\
\text { - Nordeste } \\
\text { (exceto MA) }\end{array}$ & $\begin{array}{l}\text { - Sudeste } \\
\text { - Sul (exceto SC) } \\
\text { - Centro-oeste (exceto } \\
\text { MT) } \\
\text { - Nordeste (somente } \\
\text { CE, PB, PE e RN) } \\
\text { - Norte (somente AM) }\end{array}$ & $\begin{array}{l}\text { - Sudeste } \\
\text { - Sul } \\
\text { - Centro-oeste } \\
\text { (exceto MT) } \\
\text { - Nordeste }\end{array}$ & $\begin{array}{l}\text { - Nordeste } \\
\text { (somente SE, } \\
\text { AL, BA) }\end{array}$ & $\begin{array}{l}\text { - Sudeste } \\
\text { (somente SP) } \\
\text { - Sul (somente } \\
\text { RS) }\end{array}$ \\
\hline N. de lojas 2008 & 597 & 539 & 345 & 74 & 29 \\
\hline $\begin{array}{l}\text { N. de funcionários } \\
2008\end{array}$ & 70.656 & 65.144 & 74.456 & 9.000 & 8.800 \\
\hline $\begin{array}{l}\text { Possui relatório } \\
\text { social }\end{array}$ & Sim & $\operatorname{sim}$ & $\operatorname{sim}$ & Não & não \\
\hline Relatório no GRI & Não & $\operatorname{sim}$ & $\operatorname{sim}$ & Não & não \\
\hline
\end{tabular}

Figura 2: Contextualização das empresas analisadas

Fonte: Elaborado pelas autoras, com base em informações disponíveis no endereço eletrônico das empresas (Gbarbosa, 2010; Grupo Carrefour, 2010a; Grupo Pão De Açúcar, 2010a; Wal Mart, 2010a; Zaffari, 2010), e em Bueno, S. (2010), Cencosud (2008).

Após a escolha dos supermercados a serem analisados, levantou-se os relatórios de sustentabilidade de cada um. Apenas os três maiores possuem tais relatórios publicados na internet: Grupo Carrefour (2010b), Grupo Pão De Açúcar (2010b), Wal Mart (2010b). Não foram 
encontrados tais relatórios dos outros dois supermercados, GBarbosa e Zaffari, e por este motivo eles foram excluídos da análise.

Os dados encontrados nos relatórios de sustentabilidade dos três maiores supermercados foram categorizados, então, na estrutura matricial proposta por Aligleri (2008), considerando as áreas organizacionais e os stakeholders envolvidos. No entanto, a classificação das ações seguiu a descrição sobre o que compõe cada etapa do modelo de Porter e Kramer (2006). Desta forma, há algumas modificações entre a classificação proposta por Aligleri (2008) e a análise e julgamento das autoras deste artigo.

As práticas de "Boa Cidadania", que correspondem à $1^{\text {a }}$ etapa (Boa Cidadania) do modelo de Porter e Kramer (2006), e que não são classificadas por área organizacional por Aligleri (2008), são apresentadas separadamente na figura 3. Os principais stakeholders são identificados logo após a descrição de cada ação, de acordo com as seguintes siglas: comunidade (COM), público interno (PIN), cliente (CLI), meio ambiente (MAM), fornecedor (FOR), órgãos de regulamentação (ORR).

Diversas empresas no mercado em geral, e não apenas no setor varejista, utilizam a RSC apenas como uma ferramenta de marketing para fortalecer sua imagem, sem efetivamente possuírem ações de impacto social. Mesmo entre as ações que têm algum impacto, as de Boa Cidadania, ou seja, as que são relacionadas às estratégias responsivas, acabam recebendo maior destaque na comunicação corporativa. Tal foi constatado em recente estudo de Hamza e Dalmarco (2011), junto a 950 consumidores brasileiros. Apesar de serem as ações menos relevantes do modelo de Porter e Kramer (2006), em geral, são as que têm maior lembrança junto à sociedade.

Por outro lado, pode-se constatar que os supermercados analisados também possuem ações de RSC estratégicas que muitas vezes não são largamente divulgadas ao seu público-alvo.

\begin{tabular}{|c|l|}
\cline { 2 - 3 } \multicolumn{1}{c|}{$\begin{array}{c}\text { Comuns aos } \\
\text { três } \\
\text { varejistas } \\
\text { analisados }\end{array}$} & $\begin{array}{l}\text { Boa Cidadania } \\
\text { (COM/FOR/ORR) }\end{array}$ \\
\hline - Apoio a práticas culturais e esportivas na comunidade (COM) \\
- Campanhas de conscientização da população (COM) \\
- Criaço de Instituto (COM)
\end{tabular}

Figura 3: Práticas de Boa Cidadania (etapa 1) exercidas pelos três maiores supermercados brasileiros

Fonte: Elaborado pelas autoras

Ao analisar os pontos comuns entre CBD, Carrefour e Wal-Mart (ilustrados na figura 4 a seguir), nas duas etapas seguintes (mitigar danos causados por atividades da cadeia e transformar atividades da cadeira de valor) do modelo de Porter e Kramer (2006), surgem duas constatações importantes. Uma delas é a maior similaridade de ações para "Transformar Atividades da Cadeia de Valor" em diferentes áreas organizacionais (em especial na relação com os fornecedores). Nota-se,

Revista de Gestão Social e Ambiental - RGSA, São Paulo, v. 6, n. 3, p. 78-95, set./dez. 2012. 
portanto, que existe um direcionamento comum das práticas de RSC para o setor supermercadista, que pode servir como exemplo aos demais varejistas nesta etapa específica.

A segunda constatação é que há poucas ações similares no que tange à área de logística, o que é um ponto de preocupação, uma vez que se trata de uma área de alto impacto ambiental dos fornecedores, em razão do uso de transportes de carga que geram alta queima de combustível fóssil. No entanto, existem ações por parte de um ou dois dos supermercados analisados (mas nunca das três organizações analisadas) para: (I) incentivar o uso de combustíveis de fontes renováveis; (II) redução de consumo de combustível, por meio de inovação tecnológica em veículos; (III) otimização de transporte logístico em parceira com fornecedores (back haul), e (IV) utilização de materiais sustentáveis na construção dos veículos.

\begin{tabular}{|c|c|c|}
\hline & RSC Responsiva & RSC Estratégica \\
\hline & $\begin{array}{c}\text { Mitigar danos causados por } \\
\text { atividades da cadeia }\end{array}$ & $\begin{array}{c}\text { Transformar atividades da } \\
\text { cadeia de valor }\end{array}$ \\
\hline Logística & & $\begin{array}{l}\text { - Estações de recebimento de embalagens pós- } \\
\text { consumo e óleo de cozinha usado (MAM) }\end{array}$ \\
\hline $\begin{array}{l}\text { Operação de } \\
\text { Loja }\end{array}$ & $\begin{array}{l}\text { - Conscientização e informação sobre o } \\
\text { meio ambiente e práticas sustentáveis } \\
\text { (CLI) } \\
\text { - Coleta seletiva das lojas (MAM) }\end{array}$ & $\begin{array}{l}\text { - Redução do consumo de energia e água das lojas, } \\
\text { por meio de otimização de processos e substituição } \\
\text { de equipamentos (MAM) }\end{array}$ \\
\hline Compras & $\begin{array}{l}\text { - Auditoria de higiene e condições de } \\
\text { trabalho junto aos fornecedores (FOR) }\end{array}$ & $\begin{array}{l}\text { - Certificação dos produtores nos temas ligados ao } \\
\text { meio ambiente, higiene, segurança alimentar, } \\
\text { relação com funcionários, e colaboradores, } \\
\text { aspectos legais e tributários (FOR/ORR) } \\
\text { - Pactos para cadeias de soja e pecuária, evitando } \\
\text { compra de fornecedores em listas sujas do governo } \\
\text { (FOR/MAM) } \\
\text { - Compra de produtos orgânicos (FOR/COM) }\end{array}$ \\
\hline $\begin{array}{l}\text { Recursos } \\
\text { Humanos }\end{array}$ & $\begin{array}{l}\text { - Política de treinamento (PIN) } \\
\text { - Divisão de controle de riscos \& saúde } \\
\text { ocupacional (PIN) }\end{array}$ & $\begin{array}{l}\text { - Incorporar a diversidade como um valor } \\
\text { organizacional (PIN/COM) }\end{array}$ \\
\hline $\begin{array}{l}\text { Marketing e } \\
\text { Vendas }\end{array}$ & $\begin{array}{l}\text { - Incentivo ao uso de sacolas } \\
\text { reutilizáveis (CLI) } \\
\text { - Oferecer serviço de atendimento ao } \\
\text { cliente -SAC (CLI) }\end{array}$ & - Venda de sacolas retornáveis (CLI/MAM) \\
\hline $\begin{array}{l}\text { Administração } \\
\text { Geral }\end{array}$ & $\begin{array}{l}\text { - Código de ética e disseminação de } \\
\text { valores (PIN/FOR) } \\
\text { - Possui política explícita de governança } \\
\text { corporativa (PIN) }\end{array}$ & $\begin{array}{l}\text { - Publicar relatório de sustentabilidade } \\
\text { (COM/CLI/PIN) } \\
\text { - Promover diálogo com clientes (CLI) }\end{array}$ \\
\hline
\end{tabular}

Figura 4: Ações comuns exercidas pelos três maiores supermercados brasileiros, nas etapas 2 e 3 do modelo de Porter e Kramer (2006)

Fonte: Elaborado pelas autoras.

As ações de "Filantropia Estratégica" são as que têm maior impacto para o negócio principal dos supermercados, e a análise dos relatórios mostrou não haver similaridade entre as ações praticadas pelos três varejistas, o que aponta que cada empresa possui uma estratégia própria, e adequa suas ações de RSC à mesma. Tal procedimento é adequado à discussão anterior, na revisão da literatura. As ações da "Filantropia Estratégica" de cada supermercado devem ser específicas a cada organização e são apresentadas na figura 5.

\section{Filantropia Estratégica}

- Projeto de otimização de transporte logístico, minimizando emissão de gases e queima de combustível (FOR/MAM) 


\begin{tabular}{|c|c|}
\hline Carrefour & $\begin{array}{l}\text { - Projeto de otimização de transporte logístico, minimizando emissão de gases e } \\
\text { queima de combustível (FOR/MAM) } \\
\text { - Programa Garantia de Origem: selo internacional do grupo que exige cumprimento } \\
\text { de rígidas normas ambientais e sociais, além de comprovação de manejo responsável e } \\
\text { rastreado (CLI/FOR) } \\
\text { - Participação em programa internacional para promover a sustentabilidade na cadeia } \\
\text { produtiva de alimentos (FOR/ORR) } \\
\text { - Criação de marca própria com exigência de certificação dos fornecedores em relação } \\
\text { a práticas de RSC, meio ambiente, saúde e segurança do trabalho(FOR/ORR) }\end{array}$ \\
\hline Wal-Mart & $\begin{array}{l}\text { - Desenvolvimento de fornecedores a partir de treinamentos, estimulando a } \\
\text { formalização e profissionalização de pequenos e médios fornecedores locais } \\
\text { (FOR/COM) } \\
\text { - Contratação de jovens formados pelos programas do Instituto (COM/PIN) } \\
\text { - Curso que visa fortalecer o conceito de sustentabilidade e disseminar práticas (PIN) } \\
\text { - Estímulo à adoção de práticas sustentáveis (PIN) } \\
\text { - Cobertor de PET reciclado marca própria (CLI/MAM) } \\
\text { - Sabão em pó Ariel Ecomax, em parceria com a Procter \& Gamble (CLI/MAM) } \\
\text { - Sabão TopMax, feito de óleo coletado nas lojas (CLI/MAM) } \\
\text { - Programa de crédito pela não utilização de sacolas plásticas pelos clientes } \\
\text { (CLI/MAM) } \\
\text { - Programa para redução do impacto ambiental das embalagens de produtos marca } \\
\text { própria (FOR/MAM) } \\
\text { - Prêmio Varejo Sustentável, direcionado para estudantes (COM) }\end{array}$ \\
\hline
\end{tabular}

Figura 5: Ações de Filantropia Estratégica (etapa 4) exercidas pelos três maiores supermercados brasileiros Fonte: Elaborado pelas autoras.

O Wal-Mart é a empresa que mais consegue alinhar efetivamente suas práticas de RSC com a estratégia do negócio. Um bom exemplo é o desenvolvimento de produtos sustentáveis em parceria com os fornecedores. Ribeiro (2010) aponta que, por um lado, muitas empresas têm investido em ações responsáveis, seja como forma de economia (usando os recursos de modo mais eficiente), seja pelo apelo de marketing (projetando a imagem de empresa amiga do planeta) ou ainda pela oferta de produtos "ambientalmente corretos". Por outro, o estudo de Hamza e Dalmarco (2011) apontou que 62\% dos respondentes afirmaram não conhecer nenhum produto ou ação social desenvolvido pelo supermercado que frequentam. Ou seja, a resposta a essas ações ainda é fraca. Uma pesquisa do Instituto Akatu revelou que $80 \%$ das pessoas dizem valorizar os produtos verdes, mas só $30 \%$ concretizam suas intenções no ato da compra. Percebe-se que ainda existe uma longa distância entre propósito e ação (in Ribeiro, 2010).

Já de acordo com o relatório de sustentabilidade do CBD, foi identificada apenas uma ação de Filantropia Estratégica, o que aponta que a empresa ainda carece de maior integração entre as ações de RSC e sua estratégia competitiva. Apesar disso, o estudo de Hamza e Dalmarco (2011) aponta que o Pão de Açúcar é o supermercado que possui a maior quantidade de respondentes que conhecem os produtos sustentáveis comercializados ou suas ações sociais/ambientais desenvolvidas. O Carrefour, por sua vez, possui forte atuação estratégica junto a fornecedores, no que tange às ações denominadas de "Garantia de Origem".

\section{CONSIDERAÇÕES FINAIS}

Procurou-se, por meio deste artigo, trazer uma nova contribuição sobre a integração da RSC e da sustentabilidade à estratégia competitiva das organizações, com ênfase no setor supermercadista.

A análise inicial apontou que a diferença de faturamento e número de lojas e funcionários entre os três maiores supermercadistas e os dois seguintes é enorme, e que essa disparidade se reflete, inclusive, na atuação e apresentação de relatórios de sustentabilidade. Segundo Hamza e Dalmarco (2011), 32\% da amostra pesquisada, composta fortemente por indivíduos das classes A e 
$\mathrm{B}$, frequenta este tipo de varejo. Neste sentido, existe uma oportunidade para que os pequenos varejistas utilizem os relatórios de sustentabilidade dos grandes como benchmarking, adequando as práticas para suas próprias realidades.

Entre os três supermercados analisados, foi possível verificar que todos possuem ações nas quatro etapas propostas por Porter e Kramer (2006). Pela extensão e diversidade das ações desenvolvidas, nota-se que todos procuram, em maior ou menor grau, integrar as ações de RSC ao negócio principal, conforme discutido por Elkington (1994), Handy (2002), Hart e Milstein (2004), Porter e Kramer (2006), entre outros. Ainda assim, percebe-se uma boa oportunidade de maior integração das práticas de RSC à estratégia competitiva das empresas.

Apesar de ser uma discussão recente no setor varejista, as empresas começam, aos poucos, a perceber que a sustentabilidade não é um modismo nem uma forma de caridade, mas sim uma questão estratégica. Hector Nuñez, presidente do Wal-Mart no Brasil, afirma: “[...] não vamos mudar o mundo porque somos legais, mas sim porque é a estratégia mais inteligente" (Herzog, 2010, p.1).

A pressão por ações mais responsáveis por parte das empresas vem crescendo, conforme aumenta a consciência sobre a limitação dos recursos naturais do planeta e seu impacto sobre a sociedade. As empresas que melhor souberem desenvolver ações sustentáveis alinhadas ao negócio, envolvendo não apenas seu público interno, mas todos os seus stakeholders, têm maior chance de sobrevivência no longo prazo.

Por fim, este artigo possui algumas limitações. A primeira delas refere-se ao setor analisado, de supermercados, sendo que as análises apresentadas não podem ser inferidas para outros setores. Além disso, este estudo teve caráter exploratório, por meio do levantamento de dados secundários disponíveis na internet. Portanto, não é possível analisar relações de causa e efeito sobre o nível de integração da RSC ao negócio, e o desempenho da empresa no mercado (por exemplo, nível de preferência do cliente, aumento de participação de mercado ou de rentabilidade etc). Sugere-se que estudos futuros sejam conduzidos no sentido de verificar estas possíveis relações.

\section{REFERÊNCIAS}

Aligleri, L. (2008). Gestão estratégica da responsabilidade social em supermercados: uma proposta para o processo de engajamento. Congresso Latino Americano de Varejo, 1. São Paulo: FGVEaesp.

Anselmsson, J., Johansson, U.(2007). Corporate social responsibility and the positioning of grocery brands: an exploratory study of retailer and manufacturer brands at point of purchase. International Journal of Retail \& Distribution Management, 35(10), 835.

Bardin, L.(1977). Análise de conteúdo. Lisboa: Edições 70.

Barroso de Siqueira, A.C.(2005). Marketing empresarial, industrial e de serviços. São Paulo: Saraiva, 465p.

Borger, F.G. (2001). Responsabilidade Social: efeitos da atuação social na dinâmica empresarial. Tese de doutorado. Faculdade de Economia, Administração e Contabilidade da Universidade de São Paulo. São Paulo.

Brundtland, G.H.(Org.) (1987). Report of the World Commission on Environment and Development: Our Common Future. UN Documents. Recuperado em 3 jul.2010, de: <http://www.un-documents.net/wced-ocf.htm>. 
Bueno, S. (2010). Zaffari fatura R\$2,1 bi e só fica atrás do Walmart. Valor Econômico. Porto Alegre, 15/04/2010. Recuperado em 8 jul.2010, de: <http://www.valoronline.com.br/?impresso/empresas/95/6210996/zaffari-fatura-r-2,1-bi-e-so-ficaatras-do-walmart>.

Cardoso, J. (2010). Grupo Pão de Açúcar recupera liderança. Valor Econômico. São Paulo, 16/04/2010. Recuperado em: 8 jul.2010, de: <http://www.valoronline.com.br/?impresso/tecnologia_\&_telecomunicacoes/277/6213118/grupopao-de-acucar-recupera-lideranca>.

Cardoso, R. (2008). Varejo sustentável. GVexecutivo, 7(5), 70.

Carroll, A.B. (1979). A three-dimensional conceptual model of corporate performance. Academy of Management Review, 4(4), 497.

., Hoy, F. (1984). Integrating corporate social policy into strategic management. Journal of Business Strategy, 4(3), 48.

(1991). The pyramid of corporate social responsibility: toward the moral management of organizational stakeholders. Business Horizons, 39, July-August.

.(1999). Corporate social responsibility: evolution of a definitional construct. Business \& Society. September, 38(3), 268.

Cencosud.(2008). Memoria Anual y Estados Financieros. Recuperado em: 15 jul.2010, de: <http://www.cencosud.cl/inver_memoria_anual_08.htm>.

Cheit, E.F. (1964). Why managers cultivate social responsibility. California Management Review, 7(1), 3, Fall.

Davis, K. (1960). Can business afford to ignore social responsibilities? California Management Review, 2(3), 70, Spring.

Donaldson, T., Preston, L.E. (1995). The stakeholder theory of the corporation: concepts, evidence, and implications. Academy of Management Review, 20(1),65.

Dos Santos, M. A. O. (2009). Achieving sustainable competitive advantage through the implementation of the societal marketing concept by a major retailer in South Africa. Journal of Global Business and Technology. 5(2), 39, Fall.

Eisenhardt, K.M.(1989). Building theories from case study research. The Academy of Management Review, 14(4), 532, October.

Elkington, J.(1994). Towards the sustainable corporation: win-win-win business strategies for sustainable development. California Management Review, 36(2), 90, Winter.

\section{March.}

.(1999). Triple bottom-line reporting: looking for balance. Australian CPA, 69(2), 18,

Freeman, R. E., Reed, D.L. (1983). Stockholders and stakeholders: a new perspective on corporate governance. California Management Review, 25(3), 88, Spring. 
Gbarbosa.(2010). Recuperado em: 11 jul.2010, de: <http://www.gbarbosa.com.br>.

Global Reporting Iniciative. (2010). About GRI. Recuperado em: 3 jul.2010, de: <http://www.globalreporting.org/Home>.

Grupo Carrefour Brasil.(2010a). Recuperado em 12 jul.2010, de: <http://www.grupocarrefour.com.br>. Acesso em: 12/07/2010 a.

Grupo Carrefour Brasil.(2010b) Relatório de Desenvolvimento Sustentável. Recuperado em: 12 jul.2010, de: <http://www.grupocarrefour.com.br/sustentabilidade/relatorio-de-desenvolvimentosustentavel/>.

Grupo Pão de Açúcar. (2010a). Recuperado em: 12 jul.2010, de: $<$ http://www.grupopaodeacucar.com.br/home.htm>.

Grupo Pão de Açúcar. (2010b). Relatório de Sustentabilidade. Recuperado em: 12 jul.2010, de: $<$ http://rigpa.grupopaodeacucar.com.br/grupopaodeacucar/web/conteudo_pt.asp?idioma=0\&conta= $28 \&$ tipo $=29910>$.

Hamel, G., Prahalad, C.K.(1995) Competindo pelo futuro: estratégias inovadoras para obter o controle do seu setor e criar os mercados de amanhã. (10 ed.). Rio de Janeiro: Campus, 377.

Hamza, K., Dalmarco, D. de A.S.(2011). A evolução do movimento do Consumo Consciente e seus impactos para as organizações: um estudo exploratório. In: Anais do Seminários em Administração, 14. São Paulo: FEA-USP.

Handy, C. (2002). Para que serve uma empresa? Harvard Business Review, 35, Dezembro.

Harris, S.M. (2007). Does sustainability sell? Market responses to sustainability certification. Management of Environmental Quality: An International Journal, 18(1), 50.

Harrison, J.(2005). Administração estratégica de recursos e relacionamentos. Porto Alegre: Bookman, 430p.

Henderson, B.D. (1991).The origin of strategy. 1989. In: Strategy: seeking and securing competitive advantage. Boston: Harvard Business School Publishing Division, 475p.

Herzog, A.L. (2010). Walmart: A vitória do pragmatismo. Recuperado em: 15 jul.2010, de: $<$ http://planetasustentavel.abril.com.br/noticia/desenvolvimento/empresa-modelo-walmartsustentavel-premio-518316.shtml>.

Instituto Ethos. (2010). $O$ Instituto Ethos. Recuperado em: 14 jul.2010, de: <http://www1.ethos.org.br/EthosWeb/Default.aspxr>.

Jones, P., Comfort, D., Hillier, D., Eastwood, I. (2005). Corporate social responsibility as a means of marketing to and communicating with customers within stores: a case study of UK food retailers. Management Research News, 28(10), 47. 
Macedo, L.C. de. (2005). A prática da responsabilidade social no setor varejista brasileiro. Monografia de curso de especialização. Programa de Engenharia de Produção da Coordenação dos Programas de Pós-Graduação da Universidade Federal do Rio de Janeiro. Rio de Janeiro.

. (2008). Responsabilidade social empresarial e sustentabilidade na cadeia de valor do varejo. Prêmio Ethos-Valor. ( $8^{\mathrm{a}}$ ed.), São Paulo.

Mattar, F.N.(1996). Pesquisa de marketing. (Edição compacta.) São Paulo: Atlas, 270 p.

Meadows, D., Raders, J., Meadows, D. (2004) Limits to Growth: the 30-year update. Vermont: Chelsea Green Publishing, 338p.

Ohmae, K.(1985). O estrategista em ação. São Paulo: Pioneira, 261p.

Pacto Global. (2013). Pacto Global - O que é. Recuperado em: 02 set.2013, de: <http:// http://www.pactoglobal.org.br/pactoGlobal.aspx>.

Parente, J.G., Terepins, F.M. (2006). Responsabilidade social empresarial do varejo no Brasil: um estudo multi casos em empresas de grande porte. Simpósio de Administração da Produção, Logística e Operações Internacionais, 9. São Paulo: FGV-EAESP.

Peccei, A. (1968). World problems in the coming decades. The American Behavioral Scientist, 11(6), 20, July-August.

Porter, M.E.(1986). Estratégia competitiva: técnicas para análise de indústrias e da concorrência. Rio de Janeiro: Campus, 362p.

, Kramer, M.R.(2006). Strategy \& Society: the link between competitive advantage and corporate social responsibility. Harvard Business Review, 1, December.

Prahalad, C. K., Nidumolu, R., Rangaswami, M.R. (2009). Why sustainability is now the key driver of innovation. Harvard Business Review, September.

Ribeiro, A. (2010). Falta combinar com o consumidor. Revista Época, 11/04/2010. Recuperado em: 30 jul.2010, de: <http://revistaepoca.globo.com/Revista/Epoca/0,„EMI132663-15259,00.html〉.

Roesch, S.M.A. (1999). Projetos de estágio e de pesquisa em administração. (2 ${ }^{\mathrm{a}}$ ed.) São Paulo: Atlas, 301p.

Sato, K.(2010). Faturamento dos supermercados de SP cresce 5,7\% em 2009, informa APAS. Valor Econômico. São Paulo, 10 maio 2010. Recuperado em: <http://www.valoronline.com.br/?online/varejo/64/6257257/faturamento-dos-supermercados-de-spcresce-5,7\%-em-2009,-informa-apas>.

Selltiz, J., Wrightsman., Cook.(1965). Métodos de pesquisa nas relações sociais. São Paulo: EPU.

Unep., Un Global Compact., Utopies.(2005). Talk the walk: advancing sustainable lifestyles through marketing and communications.

Wal Mart Brasil (2010a). Recuperado em: 12 jul.2010, de: < http://www.walmartbrasil.com.br/> . Acesso em: 12/07/2010a. 
Wal Mart Brasil. (2010b). Relatório de Sustentabilidade 2009 - exercício 2008. Recuperado em: 12 jul.2010, de: <http://www.walmartsustentabilidade.com.br/relatorios-e-cases/>.

Yin, R.K.(2001). Estudo de caso - Planejamento e métodos. (2 ${ }^{\mathrm{a}}$ ed.) Porto Alegre: Bookman, 205p.

Zaffari.(2010). Recuperado em: 11 jul.2010, de: <http://www2.zaffari.com.br>.

Recebido em: 17/10/11

Publicado em: 21/21/2012

Revista de Gestão Social e Ambiental - RGSA, São Paulo, v. 6, n. 3, p. 78-95, set./dez. 2012. 